\title{
Real-World Design as a One-Semester Undergraduate Project: Example of a Robust and Low-Cost Solar Lantern
}

\author{
Linda M. Head, Member, IEEE, Gay Canough, and Ravi P. Ramachandran, Member, IEEE
}

\begin{abstract}
The purpose of this project was to develop a rugged and efficient solar lantern. The lantern was designed to meet the requirements of persons who reside in areas in which access to the electrical grid is limited and whose resources do not permit import of electrical generation capabilities. A representative of a missionary organization operating in Africa developed the original set of specifications for the solar lantern. It will be used by the local school children for doing homework in the evening. These specifications prioritized reliability, ease of operation, rugged construction, portability, and low cost. The resulting design was realized in a single prototype. The design and construction of the prototype was completed as a student/faculty project in the Junior Engineering Clinic course at Rowan University in Glassboro, NJ. It was funded and directed by ETM Solar Works, a New York-based corporation.
\end{abstract}

Index Terms-Clinic, design, industrial project, robust, solar lantern.

\section{INTRODUCTION}

I T IS IMPORTANT to provide students with significant laboratory and design experiences throughout their full four years in engineering. At Rowan University, Glassboro, NJ, freshman students are given an opportunity in the first semester to explore all four of the engineering disciplines taught at Rowan University (electrical and computer, civil and environmental, mechanical, and chemical) while learning about engineering measurement techniques [1], [2].

In the second semester of the same year, the principles of design are introduced through an experience in competitive assessment [3]. During this second semester, small groups of students work on the investigation of a single product during the full semester. Along the way, they are introduced to new analysis techniques and computer tools while using a "hands-on/minds-on" method to learn the multidisciplinary nature of product design.

By the sophomore year, these students are ready for the next stage - actual design assignments in a well supervised but open environment. In the sophomore year, the students are given a design assignment, and again in small groups of four to six students, they all work on a single design project [4], [5]. The multidisciplinary nature of the clinics is maintained by not grouping the students by discipline, even though, at this point, they have

Manuscript received July 9, 2001; revised March 13, 2002.

L. M. Head and R. P. Ramachandran are with the Department of Electrical and Computer Engineering, Rowan University, Glassboro, NJ 08028 USA (e-mail: ravi@rowan.edu).

G. Canough is with ETM Solar Works, Inc., Endicott, NY 13760 USA.

Digital Object Identifier 10.1109/TE.2002.804396 chosen their majors. Finally, at the junior level, the students are ready to begin working on individual projects. The solar lantern project was assigned to three junior level electrical and computer engineering students.

\section{BACKGROUND}

Electric lamps or lanterns provide superior lighting for almost any application and are preferred over lighting from any other fuel source for general, localized, and orientation lighting. Candles and kerosene-type lanterns are a common source of lighting in remote areas where electric power is not routinely available. In addition, few nonwestern countries have a reliable supply of electric power, even in the more developed parts of those countries. Many times, even those who are connected to the electric grid find that they have a need for supplemental lighting at times when electricity is not available. The goal of this project was to develop lighting potential to meet these needs.

The criteria that were specified by the sponsor of this project prioritized reliability, ease of operation, rugged construction, portability, and low cost. These criteria guided many of the decisions that were made regarding components, materials, and physical design. Each of these items will be addressed here to provide explanation and justification for the design decisions.

\section{A. Reliability}

Individuals who normally use energy sources other than electricity for lighting will find advantages to having the brighter and more directional light provided by electrical lighting units. Usually, however, a relatively large investment must be made to acquire a lantern such as the one that has been designed. Candles and kerosene can be purchased in small quantities on a regular basis, but the lantern purchase can consume significant resources upfront. Over the life of the lantern, the user should realize a savings, though not initially. In addition, individuals in remote sites do not have access to repair services. Taken together, these factors mean that any substitute light source should provide a maximum length of reliable service. For this design, a minimum uninterrupted service was specified for the length of one year.

\section{B. Ease of Operation}

There are basically two reasons for designing a lantern that is easy to operate. The first reason relates to the previous topic-reliability. The lantern has been designed to 
be relatively free of complicated maintenance or operating procedures. There are only three control settings—on, off, and charging - displayed with a low-voltage indicator. The control settings are labeled symbolically rather than with words in any specific language. The internal protection circuits prevent the battery from overcharging or from deep depletion; either of these conditions can reduce battery life. The photovoltaics are an integral part of the lantern so that no connections are required, and they operate simply by being exposed to the sun with the control set to charging. The fully integrated nature of the lantern makes it simple to use. This simplicity is particularly important if the lantern is going to be used in many different physical settings and by people with different languages and different levels of exposure to technology.

\section{Rugged Construction}

The solar lantern must be able to withstand a wide variety of both climatic and use conditions. Particularly at remote sites, it may not always be possible to prevent rough use. All components of the lantern have been designed to minimize damage from collisions and from harsh weather conditions. The prototype lantern is constructed from aluminum with a clear plastic shield protecting the light source. The photovoltaics are attached to the top surface of the light shade where they are protected from the elements by a film coating. The production version of the lantern will be constructed from injection-molded plastic that will provide durability and protection for the electronic components.

\section{Portability}

To provide the most effective use of the lantern, it is important that it be easy to move from place to place in the home. The lantern will have to be set in a sunny location for charging, perhaps at a window or literally outside in the sunlight. The use location may be at a single chair for reading or at a table where people would gather to work. In a situation where the living arrangement is temporary (e.g., camping), the lantern would have to be easy to transport. Moving the lantern should be convenient; this design is as light as possible given the battery requirements, and the shape is as compact as possible given the requirements for the extent of the lighted area.

\section{E. Low Cost}

Finally, the cost must be low enough for the lantern to be available as a replacement for other common forms of lighting in remote areas. Since the initial motivation was to provide lighting at a remote mission in Africa and not to create luxury camping gear, the cost of materials and construction was kept as low as possible. The criteria that the students used was to keep the cost less than a single year's worth of candles or kerosene (approximately $\$ 60$ ).

It is clear from this expanded list of design criteria that the students faced a very challenging project. But it is the type of project that motivates the students from personal, social, and technical points of view. A description of the design process that the students pursued and the results that were obtained by the end of the first semester's work is provided in the remainder of the article.

\section{EdUCATIONAL PRINCIPLES}

The solar lantern project was designed with specific educational principles in mind. The most important principle was to approach engineering design from a holistic point of view (i.e., a point of view that would allow the students to have the opportunity to see all aspects of the development of a product). Often student assignments have a preset product, one that fits the needs of the curriculum rather than needs in the "real world." Even if the design product is a practical item, the students are aware that they are dealing with a "canned" experiment. Here, the first goal was to provide them with a problem that came from a source outside of school. The students were presented with the following problem:

There is a missionary in Africa who needs to provide a reliable lighting source for the children of his village. They work during the day in the fields and need to study at night, but the candles they currently use do not provide adequate light and are too expensive. The children study in groups at a single table.

This problem statement originated in conversations held between author Canough and a missionary who was visiting her church - the problem was real, and the students were aware of this reality. Once the situation was set, the students followed a definite series of steps that led them to the construction of the final product. With the need for a solution to a problem established, they next researched the environment and conditions in which their final product would be used; that is, they put their product in context. Though a solar lantern might be used in other areas, the need that this product must meet was very specific and tailored to a special application. This specificity required consideration in the early stages of design. The students also researched and evaluated existing products that might serve the needs of the children (such a search can often be an engineering solution to a problem) - a solution might be needed, but a new product might not. Improvements to existing designs that would better suit the current need were discussed. It was at this point that the students were most focused on the economic aspects of production; there are many costs besides direct purchase of supplies that influence the final cost of a new product. Finally, the technical details of the new design could be addressed, and construction of a prototype completed. By proceeding through the entire process, the students had the opportunity to experience a real-world, collaborative effort that included all pertinent aspects of product development. They were not limited to just the technical details of the design of a product; they began with a need and proceeded holistically through final product construction. Section IV describes the actual design process.

\section{Description of the Design PROCess}

The faculty, sponsor, and students began the semester by setting the task schedule to complete the lantern design and construction in a single semester. In retrospect, this goal was overly ambitious; however, it did set a high standard for the group. 
TABLE I

TASK PLANNING FOR SOlar LANTERn PROJECT

\begin{tabular}{|c|c|c|c|c|c|}
\hline TASK & JAN & $\underline{\text { FEB }}$ & MAR & $\underline{\text { APR }}$ & $\underline{\text { MAY }}$ \\
\hline Needs Assessment & & & & & \\
\hline $\begin{array}{l}\text { Selection of Electrical } \\
\text { Components }\end{array}$ & & & & & \\
\hline Design of Lantern Body & & & & & \\
\hline Design of Circuitry & & & & & \\
\hline Circuit Prototyping & & & & & \\
\hline $\begin{array}{l}\text { Physical Construction of } \\
\text { Lantern }\end{array}$ & & & & & \\
\hline $\begin{array}{l}\text { Installation of Electrical } \\
\text { Components }\end{array}$ & & & & & \\
\hline
\end{tabular}

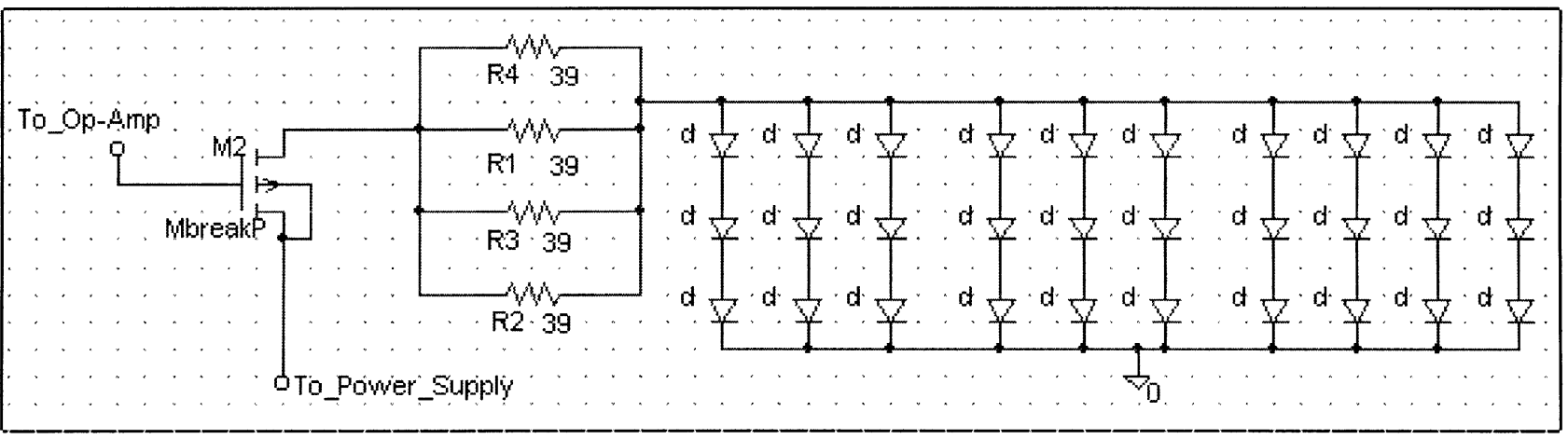

Fig. 1. Circuit diagram for light-emitting diode (LED) array.

Table I shows the organization of the tasks for the semester. The students were very excited about the project and planned to see it to completion in the span of the semester.

The needs assessment was a very important aspect of the project. This opportunity was for the students to research the context in which their product would be used and to plan a design that not only met the technical criteria but also met the personal and social needs of the young students who would be using the lantern. To accomplish the needs assessment, the students used a combination of Web searches, phone calls to relevant organizations (e.g., UNICEF and the American Red Cross), and personal interviews with faculty and students who have had contact with Third World countries.

One of the most interesting aspects of the project was the opportunity the students had to use new technologies. Although the use of solar power for battery charging is not novel, the students were able to take advantage of some of the new forms of construction. Specifically, they used the thin-film photovoltaics for the lantern. Although, LEDs do not involve a new technology, the development of white LEDs gave the students the opportunity to construct an extremely efficient lantern that would provide many hours of light on a single battery charge. In the remainder of this section, a technical description of the lantern components is provided to illustrate the depth of understanding and extent of design coordination that the students were able to achieve.

\section{A. White LEDs}

The heart of the solar lantern is the array of white LEDs. Recently developed by Siemens in Germany, white LEDs offer a long-lasting (hundreds of thousands of hours) light source that is very power efficient [6]-[8]. The efficiency is critical in the solar lantern, since the objective is to provide light for long periods of time using only a battery. In addition, white LEDs are much less fragile than are incandescent bulbs. This selection will make the lantern more rugged than lanterns that use incandescent bulbs as their light sources. Thus, white LEDs are the perfect light source for the solar lantern.

Nine white LEDs output approximately the same amount of light as one $20-\mathrm{W}$ incandescent light bulb [9]. Using this fact as a guide, the decision was to use 30 white LEDs in the lantern to produce an amount of light equivalent to that produced by a 60-W incandescent bulb. The LEDs are wired in ten parallel rows, with each row consisting of three LEDs in series (Fig. 1). Each row of LEDs will draw approximately $20 \mathrm{~mA}$ of current, and so the power dissipated by each LED can be found from 
TABLE II

COMPARISON OF LIGHT BETWEEN LEDS AND A 60-W BULB

\begin{tabular}{l|l|l}
\hline $\begin{array}{l}\text { Distance above light } \\
\text { source (inches) }\end{array}$ & $\begin{array}{l}\text { Light emitted from } \\
\text { LEDs (foot-candles) }\end{array}$ & $\begin{array}{l}\text { Light emitted from 60W bulb } \\
\text { (foot-candles) }\end{array}$ \\
\hline 6 & 230 & 180 \\
\hline 12 & 114 & 62 \\
\hline 18 & 68 & 37 \\
\hline 24 & 42 & 26 \\
\hline 30 & 27 & 17 \\
\hline 36 & 19 & 12 \\
\hline
\end{tabular}

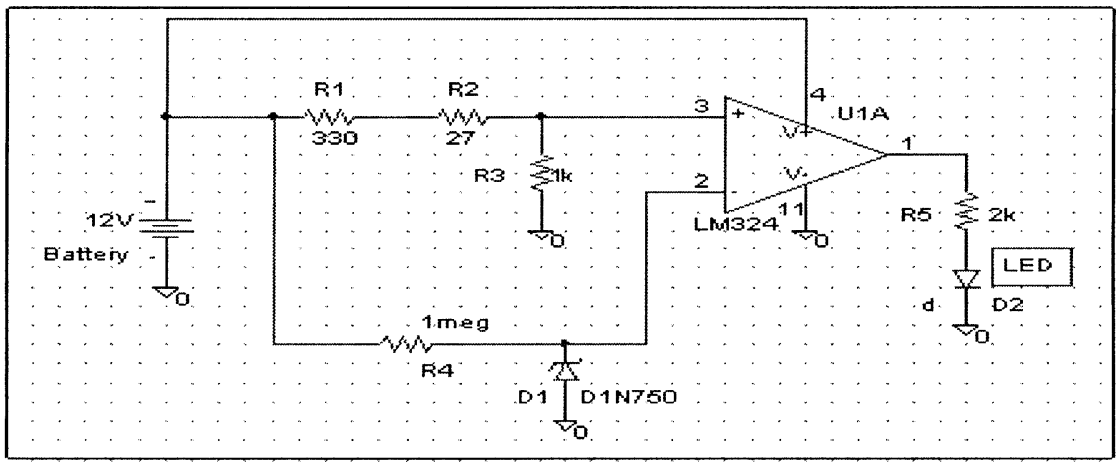

Fig. 2. Battery low-voltage indicator circuit.

$P=V I=(3.3 \mathrm{~V})(0.020 \mathrm{~A})=66 \mathrm{~mW}$. The total power dissipated by the 30 LEDs is $(30)(66 \mathrm{~mW}) \approx 2 \mathrm{~W}$.

Tests were also conducted to compare the light emitted by 27 LEDs to that emitted by a $60-\mathrm{W}$ incandescent bulb. Light measurements were made in a dark room directly above each light source. No measurements were made to the sides of the light sources, since the LEDs are very focused and do not emit much light to the sides. The results are shown in Table II.

The LEDs produced more direct light than did the $60-\mathrm{W}$ incandescent bulb. A reflecting cone was used with an array of these devices for the lantern so that the light would be more diffuse.

\section{B. Battery}

Two battery technologies were considered for the solar lantern: lithium-ion and sealed lead acid (SLA). The main advantage of lithium-ion batteries is that they are completely environmentally friendly. When finished with them, the user needs only to throw them in the garbage. Virtually all other rechargeable batteries cannot be disposed of in this manner without harm to the environment. However, lithium-ion batteries do not necessarily protect against overcharging, and they do not source as much current and voltage as SLA batteries. Thus, more than one lithium-ion battery would be necessary. Another issue is their availability. Lithium-ion batteries are less readily available for purchase.

SLA batteries were chosen for this application. They can source more voltage and current than can lithium-ion batteries, which means that only one SLA battery needs to be used in comparison to the many lithium-ion batteries needed to achieve the same capacity. SLA batteries also charge quickly, protect against overcharging, and are maintenance free. SLA batteries are fully recyclable but pose a threat to the environment if disposed of like regular trash.

A large capacity (7-Ah) SLA battery was chosen for two reasons: 1 ) the weight (5.7 lbs or $2.6 \mathrm{~kg}$ ) will ensure that the base of the lantern, which is where the battery will reside, will be sufficiently heavy to prevent the lantern from being easily tipped over; and 2) the larger the capacity of the battery, the longer the overall life span of the battery will be. At a battery voltage of $13.02 \mathrm{~V}$, the load the battery will see is $283 \mathrm{~mA}$ (as shown by tests). At this load, a 7-Ah battery will last for approximately $30 \mathrm{~h}$ before needing a recharge. As for overall battery life, if the lantern is used for $9 \mathrm{~h} / \mathrm{d}$ (and also recharged daily), the battery will last approximately 1200 cycles ( 1 cycle equals 1 charge and 1 discharge), or equivalently $3.28 \mathrm{a}$. At the end of $1200 \mathrm{cy}-$ cles, the battery will have been reduced to $60 \%$ of its original capacity.

A battery indicator circuit is provided to monitor the charge state. It is comprised of three separate but identical indicator circuits. The schematic for one of these circuits is shown in Fig. 2. Green, yellow, and red LEDs turn off consecutively as the battery voltage drops. This feature allows the user to know approximately how much time is left on a single charge of the battery.

A low-voltage cutoff circuit is used to prevent the battery from discharging beyond the manufacturers recommended value. A schematic is shown in Fig. 3. It is simple in nature and is composed of a voltage divider, a shunt regulator, a comparator (the op-amp from an LM614 IC chip), and a pMOS transistor. When the battery voltage is reduced to $10.5 \mathrm{~V}$, the output of the voltage divider can be calculated 


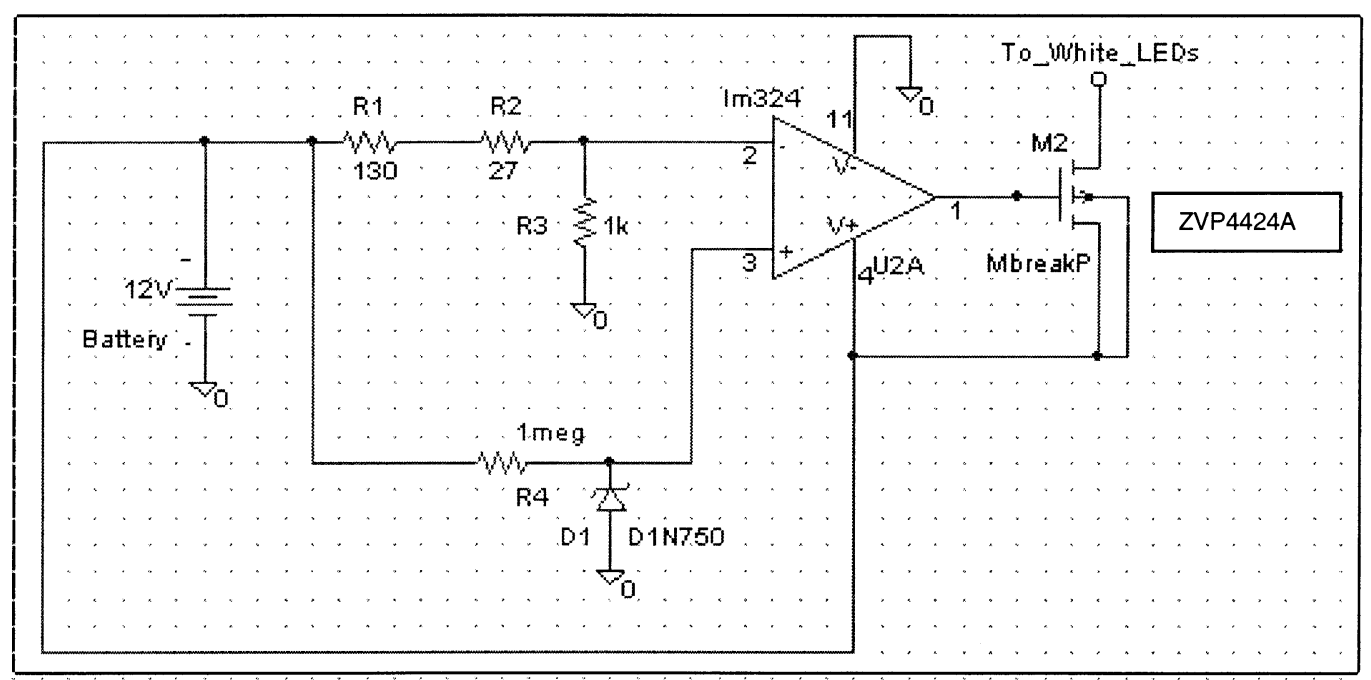

Fig. 3. Low-voltage cutoff circuit.

TABLE III

Test Results For THIN-Film Solar PANELS

\begin{tabular}{c|c|c|c}
\hline $\begin{array}{c}\text { Panel } \\
\text { Number }\end{array}$ & Time of Day & Open Circuit Voltage & $\begin{array}{c}\text { Short Circuit } \\
\text { Current }\end{array}$ \\
\hline 1 & $1: 15 \mathrm{pm}$ & $4.10 \mathrm{~V}(\mathrm{dc})$ & $32.6 \mathrm{~mA}$ \\
\hline 1 & $2: 30 \mathrm{pm}$ & $4.03 \mathrm{~V}(\mathrm{dc})$ & $34.5 \mathrm{~mA}$ \\
\hline 2 & $2: 46 \mathrm{pm}$ & $4.01 \mathrm{~V}(\mathrm{dc})$ & $40.6 \mathrm{~mA}$ \\
\hline
\end{tabular}

$V_{\text {out }}=(((1000)(10.5)) /(1000+130+27))$ and equals $9.075 \mathrm{~V}$. If the battery voltage falls below 10.5 , the voltage at the comparator's negative terminal will fall below 9.075 and turn off the current supply to the LEDs.

\section{Solar Panels}

There were three main types of solar panels to be considered: monocrystalline silicon, polycrystalline silicon, and silicon amorphous cells [10]. Monocrystalline silicon cells are the most common and also boast the highest efficiency levels. Polycrystalline silicon is also fairly common, although it does not have the same high-energy production as monocrystalline silicon. Amorphous silicon is the newest product available on the market [11], [12]. It is available in thin sheets and thus allows for more versatile placement. Unfortunately, it is not as efficient as the other two types.

Monocrystalline silicon has, by far, the highest and most stable output. It has the highest cost of any of the three major types as well but is one of the most rugged and rigid panels. Polycrystalline silicon allows for faster energy production than either of the other two types. It is also slightly less expensive than the monocrystalline silicon. Amorphous silicon comes in extremely thin sheets and is thus lightweight. These are the lowest cost solar panels and the quickest to manufacture. They are also fairly resilient to outdoor conditions.

Unfortunately, there are drawbacks to each of these. Monocrystalline silicon is one of the heaviest solar panels available. This weight places restrictions on where the solar panel can be mounted because some materials may not support the weight. Polycrystalline silicon is also fairly heavy. It is also plagued by lower energy output and is less efficient than is monocrystalline silicon. Amorphous silicon solar cells are the least efficient of the three.

Because of its lower cost, small size, and ruggedness, the choice was to use the amorphous thin-film, silicon solar panels. For the prototype, 30 small panels were used; each rated at $3 \mathrm{~V}$ and $50 \mathrm{~mA}$. They are wired in six parallel rows of five panels in series. This configuration is rated at $300 \mathrm{~mA}$ at $15 \mathrm{~V}$. Tests done (see Table III ) on the small solar panels showed that the open-circuit voltages and short-circuit currents of the panels were less than specified by the manufacturer. (According to manufacturer's specifications, open-circuit voltage should be $4.4 \mathrm{~V}$; short-circuit current should be close to $64 \mathrm{~mA}$. Weather conditions were sunny and clear. The panels were inside and pointed toward the sun through a window. ) Therefore, it is expected that the panel array will not output the full $15 \mathrm{~V}$ and $300 \mathrm{~mA}$. These measurements were taken with standard multimeters and were intended only to verify that the panels were operating rather than as an attempt to reproduce tests performed by the manufacturer.

To simplify manufacturing of an actual production model, one large panel would replace the 30 smaller ones. Such a panel is available from Uni-Solar and is less expensive than is the small panel array. The Uni-Solar panel has its own polymer lamination to shield it from the weather and will eliminate the need to wire 30 individual panels.

These are the major components that were used in the construction of the prototype solar lantern. The integration of these 


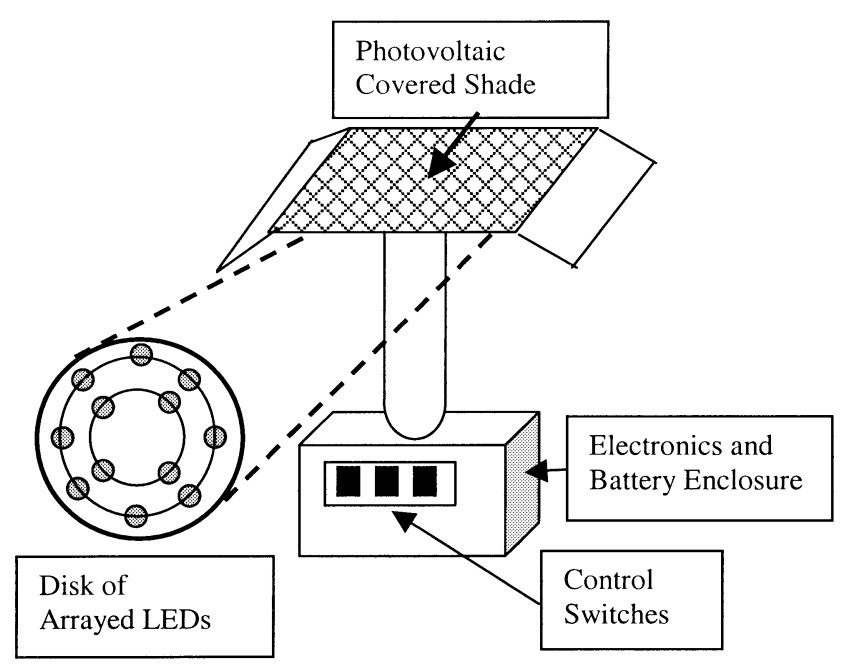

Fig. 4. Overall physical design of the lantern.

components into the final product design will be described in Section V.

\section{PRODUCT INTEGRATION}

Fig. 4 shows the overall physical design that was used in the construction of the prototype. The individual components labeled in Fig. 4 have been described previously. The body of the lantern was constructed from aluminum. This material is not the best for this particular application; however, it was available as an option for the prototype. The recommendation for the "use" or production version is that it be crafted in injection-molded plastic. Injection-molded plastic will be an ideal material for conditions in which the lantern will be used.

The integration of the electronics required wiring from the base where the battery and electronics were enclosed to the "shade" where the photovoltaic cells were positioned, and the disk of arrayed LEDs was mounted under the "shade." The concave disk for the LEDs was constructed of a reflecting material, and the individual LEDs were distributed to create reflections that provided a 4-ft-diameter circle of light when the lantern is used at a table. Fig. 5 shows the block diagram for the solar lantern's electrical system. The design and construction of this system presented a demanding design challenge for the students and was an excellent learning experience. The experience provided them with the opportunity to do more than simply create a circuit for a single function. They also learned how to integrate various electronic and electrical components into a working system.

\section{CONCLUSION}

This project was extremely successful both as a design experience for the students and as a learning experience for the faculty members, who were involved in supervising a "startfrom-scratch" product design. The initial project definition was not specific in terms of the technical specifications that were required. Rather, the charge to the design group was more general.

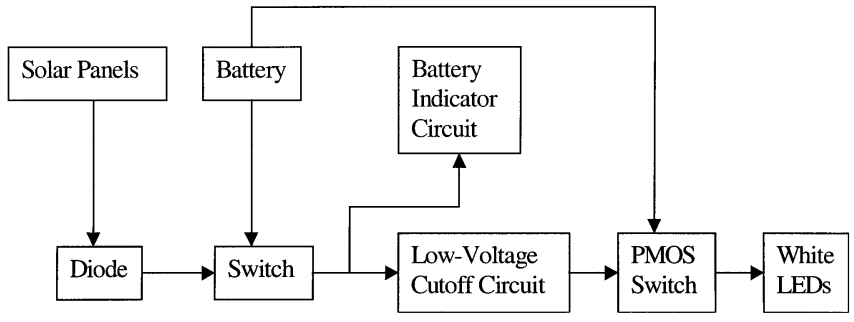

Fig. 5. Block diagram for the solar lantern's electrical system.

Their only final goal was to create a solar lantern that is economical to produce and can be used in remote areas by children doing their school work. This assignment created the ideal situation for the students; they were faced with learning more not only about the technology but also about the context in which the technology is to be used. This is a lesson that faculty members often do not have "time" to teach students in the typical classroom situation. Rowan University’s clinic program in engineering is not only the ideal place to explore traditional technical design but also a place created where students have an opportunity to work with the interactions between engineering practice and the broader social concerns. This important interaction is one of which all students should be aware.

The students who worked on the solar lantern design team set the ground rules for their collaboration, using interest and inclination as their criteria. The work was divided equitably, based on their decisions about which tasks required individual focus and which required a group effort. For instance, the three students worked collaboratively on the design of the circuitry; this area was one in which they felt that they could assist each other and brainstorm on design. On the other hand, one student constructed the circuit, a job in which too many hands would have slowed, rather than enhanced, progress.

At the completion of the semester, the students sat with the faculty and reviewed their progress on the technical aspects of the project, as well as their progress as an engineering team. They talked about their group process in terms of coordination, collaboration, design competencies, and interaction with the project's sponsor. In each of these categories, there were successes and failures, but all agreed that they had learned significant lessons that would help them as they pursue other design projects.

\section{REFERENCES}

[1] R. P. Hesketh, K. Jahan, A. J. Marchese, C. S. Slater, J. L. Schmalzel, T. R. Chandrupatla, and R. A. Dusseau, "Multidisciplinary experimental experiences in the Freshman Engineering Clinic at Rowan University," presented at the ASEE Annu. Conf. and Exposition, 1997. Session 2326.

[2] K. Jahan, R. A. Dusseau, R. P. Hesketh, A. J. Marchese, R. P. Ramachandran, S. A. Mandayam, and J. L. Schmalzel, "Engineering measurements in the Freshman Engineering Clinic at Rowan University," presented at the ASEE Annu. Conference. and Exposition, Seattle, WA, June 28-July 1, 1998. Session 1326.

[3] R. P. Ramachandran, J. L. Schmalzel, and S. A. Mandayam, "Engineering principles of an electric toothbrush," presented at the ASEE Annu. Conf. and Exposition, Charlotte, NC, 1999. Session 2253.

[4] J. A. Newell, A. J. Marchese, R. P. Ramachandran, B. Sukumaran, and R. Harvey, "Multidisciplinary design and communication: A pedagogical vision," Int. J. Eng. Educ., vol. 15, no. 5, pp. 376-382, 1999. 
[5] R. P. Ramachandran, J. A. Newell, A. J. Marchese, B. Sukumaran, J. L. Schmalzel, H. Benavidez, and J. Haynes, "A pedagogical concept of integrating multidisciplinary design and technical communication," presented at the ASEE Annu. Conf. and Exhibition, St. Louis, MO, June $18-21,2000$. Session 2325 .

[6] J. Kido, M. Kimura, and K. Nagai, "Multilayer white light-emitting organic electroluminescent device," Science, vol. 267, pp. 1332-1334, 1995.

[7] J. E. Littman and S. A. VanSlyke, "White light-emitting internal junction organic electroluminescent device,", 1995.

[8] M. Granström and O. Inganäs, "White light emission from a polymer blend light-emitting diode," Appl. Phys. Lett., vol. 68, pp. 147-149, 1996.

[9], Jade Mountain Inc., Boulder, CO, U.S.A. [Online]. Available: www.jademountain.com

[10] L. L. Kazmerski, "Photovoltaics: A review of cell and module technologies," Renewable Sustainable Energy Rev., vol. 1, pp. 71-170, 1997.

[11] J. C. Yang, "Advances in amorphous silicon alloy technology-The achievement of high-efficiency multijunction solar cells and modules," Prog. Photovoltaics Res. Applicat., vol. 6, pp. 181-186, 1998.

[12] H. Ullal, K. Zweibel, and B. G. von Roedern, "Current status of polycrystalline thin-film technologies," in Proc. 26th IEEE Photovoltaic Specialists Conf., Anaheim, CA, Sept. 29-Oct. 3 1997, pp. 301-305.
Linda M. Head (S'83-M'84) received the Ph.D. degree from the University of South Florida, Tampa, in 1991.

She worked at the State University of New York, Binghamton, prior to joining Rowan University, Glassboro, NJ, in 1998. Currently, she is an Associate Professor in the Department of Electrical and Computer Engineering at Rowan University.

Gay Canough received the Ph.D. degree in physics from Notre Dame University, Notre Dame, IN.

She is the Chief Executive Officer of ETM Solar Works, Inc., Endicott, NY. She has worked in both industry and academia while pursuing her entrepreneurial interests full time.

Ravi P. Ramachandran (S'87-M'90) received the Ph.D. degree from McGil University, Montreal, Canada, in 1990.

He worked at AT\&T Bell Laboratories and Rutgers University, Piscataway, NJ, prior to joining Rowan University, Glassboro, NJ. Currently, he is an Associate Professor in the Department of Electrical and Computer Engineering at Rowan University. 